\title{
REFLEXÕES SOBRE A SEQUÊNCIA ESPIRAL DO DESENVOLVIMENTO MUSICAL ${ }^{1}$
}

\section{REFLECTIONS ON THE SEQUENCE OF MUSICAL DEVELOPMENT}

Keith Swanwick

Tradução: Cecilia Cavalieri França MUS Produção musproducao@gmail.com

Revisão: Marcus Vinícius Medeiros Pereira ${ }^{3}$ Universidade Federal de Juiz de Fora (UFJF) marcus.medeiros@ufjf.edu.br 


\section{Resumo}

Este artigo revisita a sequência do desenvolvimento musical levando em conta as origens e o desenvolvimento da teoria juntamente com a organização e a classificação dos dados: as composições das crianças. Enfatiza novamente a natureza cumulativa e recursiva da espiral e traz à tona a relação dinâmica entre os seus lados esquerdo e direito. No texto, afirma-se a natureza essencialmente qualitativa do estudo e são discutidas algumas possibilidades para o futuro, juntamente com um modelo bidimensional para o currículo e para a avaliação dos alunos concebido com base nos resultados relacionados à espiral e nas atividades que promovem e sustentam o desenvolvimento musical.

Palavras Chave: Desenvolvimento musical. Modelo espiral. Educação musical.

\section{Abstract}

The sequence of musical development is revisited. The origins of the underlying and evolving theory are considered, along with organisation and classification of the data of children's compositions. The cumulative and recursive nature of the spiral is re-emphasised and the dynamic relationship between the left and right side is clarified. The essential qualitative nature of the study is asserted and some possibilities for the future are considered, along with a two dimensional model for curriculum and student evaluation based on spiral-related outcomes and the musical activities that promote and sustain them.

Keywords: Musical development. Spiral model. Music education.

1. O artigo aqui traduzido para a língua portuguesa será publicado em uma edição especial do British Journal
of Music Education, da Cambridge University Press, em novembro de 2021 em comemoração aos 35 anos da
publicação do artigo em que Swanwick e Tillman apresentaram o Modelo Espiral de Desenvolvimento Musical.

2. Educadora musical, escritora, compositora e pesquisadora com extensa produção e intensa atuação na área. É Ph.D e mestra em Educação Musical pela Universidade de Londres, especialista em Educação Musical e bacharela em Piano pela UFMG, onde foi professora e pesquisadora entre 1999 e 2010. É diretora da MUS Produção, onde atua com formação de professores e produção de conteúdo. É autora de inúmeras obras para educação musical, incluindo livros para professores e para o ensino escolar, como a coleção didática Trilha da Música, livros paradidáticos, de literatura infantojuvenil com temática musical e para piano, jogos musicalizadores, como o ScrapMusic ${ }^{\circledR}$, vídeos de animação e CDs autorais.

3. Doutor em Educação pela Universidade Federal de Mato Grosso do Sul (UFMS). Professor associado da Faculdade de Educação da Universidade Federal de Juiz de Fora (UFJF), onde atua como docente permanente do Programa de Pós-Graduação em Educação. É também professor do Programa de Pós-Graduação em Música da Universidade de Brasília. Lidera o Grupo de Estudos e Pesquisas Observatório das Práticas Musicais, atua como pesquisador do Observatório de Cultura Escolar (UFMS) e é membro associado do LCT Centre for Knowledge-Building (Universidade de Sidney). É o atual presidente da Associação Brasileira de Educação Musical (ABEM). 


\section{Prólogo}

Keith Swanwick, professor emérito do Instituto de Educação da Universidade de Londres, tem sido um dos mais influentes autores na área da Educação Musical em todo o mundo e especialmente no Brasil, tendo participado de inúmeros eventos no país e orientado um número expressivo de mestres e doutores brasileiros.

Swanwick graduou-se com distinção na prestigiosa Royal Academy of Music e atuou como professor em várias escolas e universidades. Com uma prolífica carreira que já conta com seis décadas, Keith Swanwick foi o primeiro presidente da British Association for Education in the Arts, em 1987, e ocupou a primeira cátedra de Educação Musical na Europa. Ao lado de John Paynter, foi editor do British Journal of Music Education entre 1984 e 1998. Também presidiu, entre 1991 e 1995, o Music Education Council do Reino Unido.

Como pesquisador, dedicou-se à teoria e prática em Educação Musical, destacando-se o modelo filosófico $C(L) A(S) P$ - que preconiza uma educação musical abrangente, priorizando o envolvimento direto com música em diferentes e interligadas modalidades de comportamento musical - e o Modelo Espiral de Desenvolvimento Musical - que descreve o desenrolar da consciência em relação aos elementos do discurso musical. Dentre seus livros, destacam-se A Basis for Music Education, de 1979; Music Mind and Education (traduzido recentemente para o português), de 1988; e Musical Knowledge: Intuition, Analysis and Music Education, de 1994.

O reconhecimento internacional de sua contribuição para a filosofia e psicologia da música e da educação musical levou-o a ministrar palestras, cursos e oferecer consultorias em mais de 20 países. Em 2019, a Incorporated Society of Musicians (ISM) outorgou-lhe o seu Lifetime Achievement Award, um prêmio pelo conjunto de sua obra, oferecido em "ocasiões extremamente raras" para aqueles que se comprometeram, ao longo de sua vida, em causar um impacto extraordinário no avanço da música e na produção musical no Reino Unido, por meio de composição, performance, musicologia ou pela educação.

Marcus Medeiros 


\section{O contexto}

É um prazer e um privilégio contribuir para esta celebração de 35 anos da publicação do artigo escrito por mim e June Tillman (SWANWICK; TILLMAN, 1986) no British Journal of Music Education. O referido estudo envolveu inúmeras horas de trabalho com crianças, muito pensamento focado e bastante cooperação. Na época, sabíamos que ele poderia criar um rebuliço. Quando o artigo foi submetido pela primeira vez, dentre as respostas do conselho editorial, algumas foram bastante favoráveis, com comentários variados, por exemplo, "era isso o que estávamos esperando", ou "isso deve ser publicado sem dúvida, mas...". Uma das preocupações foi que o "mas" parecia questionar o efeito que tal modelo poderia surtir no então "movimento de criatividade". Posteriormente, nós dois tivemos longas discussões com um colega que estava preocupado em codificar as composições das crianças dessa forma. Naquela época, meu coeditor demonstrava algum receio de que o estudo pudesse ter migrado para seu território. No entanto, de forma geral, os educadores musicais mostravam sinais de que havia algo no nosso estudo com que conseguiam se identificar.

\section{Precisamos de um mapa do desenvolvimento musical?}

Para uma boa parte da atividade musical, a referência a qualquer tipo de esquema de desenvolvimento pode ser desnecessária ou inadequada. Este autor tem idade suficiente para ter muitos parentes jovens. Um deles só quer saber de compor, mas principalmente tocar músicas pop e rock em uma banda. O outro é um artista extrovertido que atua em muitos ambientes. Um terceiro se dedicava, sem entusiasmo, ao fagote na orquestra da escola, mas desistiu assim que possível; agora, cria sua própria música de forma eletrônica. Há, ainda, uma outra que não tem vontade de se apresentar ou compor: o que ela realmente quer é ser uma jornalista de música pop. Cada um encontrou seu próprio caminho informalmente, com o mínimo de instrução e sem a necessidade de modelos complicados de desenvolvimento musical - embora possamos reconhecer seu desenvolvimento musical ao ouvi-los.

Porém, quando o ensino está envolvido, quando alguém está "inscrito" em um processo de educação musical de algum tipo, podemos ver que há algum "valor agregado" ao aprendizado autodidata ou intuitivo. Mesmo nos ambientes mais informais, é bem-vindo o entendimento do que seja o desenvolvimento musical, bem como das formas possíveis de reação e das atividades para promovê-lo da melhor maneira. Vejamos um exemplo na aquisição da linguagem. Durante uma caminhada, encontramos uma família com três filhos. Uma menina de um a dois anos se aproximou, olhou para mim, apontou e disse "cachorro", utilizando a linguagem de modo condizente com a sua idade. E, de fato, havia um cachorro logo atrás de mim. Qual deveria ser minha resposta a este pequeno repertório linguístico? Eu disse algo como "obrigado, não tinha visto o cachorro". Então seguimos em frente. Se eu fosse o seu pai (ou professor), eu poderia interagir com a menina e possivelmente estimular o desenvolvimento de sua linguagem por meio de perguntas pertinentes como "você gosta de cachorros?" ou "de que cor era o cachorro?". Como eu havia feito uma avaliação informal do nível linguístico dessa garotinha supersociável, eu sabia que seria totalmente inade- 
quado perguntar "o que você acha da passagem da tragédia shakespeariana na qual Marco Antônio diz 'Clamem destruição e soltem os cães da guerra'?". ${ }^{4}$ No entanto, essa pergunta caberia se eu estivesse conversando com uma criança mais velha que estudasse Shakespeare na aula de literatura inglesa.

Com certeza, é possível dizer o mesmo em relação ao desenvolvimento musical. É importante que os professores saibam quais respostas podem ou não ser adequadas em relação ao que os alunos estejam fazendo, o que podemos esperar a seguir e como podemos contribuir para seu desenvolvimento. Embora a composição em sala de aula seja bem reconhecida como atividade, não tenho certeza de que todos os professores envolvidos se sintam confiantes para reagir de forma a promover o desenvolvimento dos seus alunos.

\section{A evolução da teoria}

Ao longo desses 35 anos, recebi muitas respostas positivas, incluindo dezenas de mensagens espontâneas sobre a utilidade da sequência espiral de desenvolvimento musical. Em minhas viagens, encontrei muitos professores que se identificaram com a espiral, desde uma professora do ensino fundamental nos EUA, que disse que conseguia reconhecer a produção musical de todos os seus alunos pelas lentes da sequência, ao kuwaitiano que conheci no Iraque, que relatou que o modelo poderia ajudá-lo a avaliar a música dos estudantes universitários aos quais ensinava no Kuwait.

Ao longo do tempo, tentei abordar algumas das questões pendentes, especialmente em uma importante publicação, intitulada Musical Development: revisiting a generic theory ("Desenvolvimento Musical: revisitando uma teoria genérica"), que pode ser encontrada em Swanwick (2011, 2016). Em primeiro lugar, é preciso dizer que a gênese do artigo surgiu do conjunto de composições infantis que June Tillman compilou com afinco, bem como da análise sensível que fez delas. Anteriormente e em paralelo, desenvolvi meu próprio trabalho, inicialmente exposto em minha palestra de posse como professor titular da Universidade de Londres, em 1983: The Arts in Education: Dreaming or Wide Awake? ("As Artes na Educação: sonhar ou estar bem acordado?"), publicada pelo Institute of Education em 1984 e, recentemente, em Swanwick (2016). Nesse artigo, com referência específica a Piaget, discuti os conceitos de assimilação e acomodação, no que se refere respectivamente à forma musical e ao caráter expressivo, e também o conceito de domínio dos materiais sonoros. Para mim, este trio de elementos interativos - materiais, expressão e forma - compreende todos os atos de produção e compreensão musical. A terminologia, no entanto, foi adaptada especificamente para o estudo e é importante entender como foi utilizada.

4. "Cry Havoc and let slip the dogs of war?" é uma frase da tragédia Julius Caesar, de William Shakespeare (Ato 3, Cena 1), de 1599.' 


\section{Os conceitos fundamentais}

Na sequência espiral de desenvolvimento musical, o termo "materiais" diz respeito à relação entre o prazer exploratório e o interesse pelo próprio som (jogo imaginativo), cujo desenvolvimento se dá em direção ao controle desses sons. "Expressão" não significa autoexpressão, mas a expressão de ideias musicais, a princípio de maneira pessoal e espontânea e depois com um vocabulário musical socialmente compartilhado, que chamamos de vernáculo. A expressão musical diz respeito à produção e ao reconhecimento de formas expressivas, ou seja, frases, e não apenas notas ou sons isolados. Uma frase pode, é claro, ser uma única nota ou outro som, como, por exemplo, quando um trompete toca e mantém um "Lá" com um pequeno crescendo no início da abertura da ópera Rienzi, de Wagner. Este "Lá" é uma forma expressiva, ao contrário do "Lá" ouvido quando a orquestra estava afinando. O som é basicamente o mesmo, mas movemos o seu sentido, psicologicamente falando, do âmbito dos materiais para o da expressão, ou seja, da nota para a frase. O terceiro conceito é o da "forma", que não deve ser pensada em termos de convenções clássicas (como rondó, forma sonata etc.), mas, fundamentalmente, como a maneira pela qual as frases se relacionam: por repetição, contraste ou transformação.

Graças a June Tillman, tínhamos esses dados abrangentes de produções infantis e também algumas pistas para começar a agrupá-las e explorar suas características. Houve outra fonte inicial importante, a de Robert Bunting (1977), que observou estudantes compondo nos primeiros anos do ensino médio e identificou vários tipos de composição, os quais ele não classificou como em uma sequência de desenvolvimento, mas que nos deram muitos insights em nossas tentativas de identificar padrões de desenvolvimento.

Por exemplo, Bunting observou tipos de composição que chamou de 1) "modo neurológico": reações físicas diretas ao som; 2) "modo acústico": interação com o tamanho e com o design da construção; 3) "modo mecânico": influência da forma e das funções dos instrumentos musicais (por exemplo, produzir música em um xilofone com duas baquetas provavelmente produzirá melodias saltitantes, enquanto o uso de apenas um dedo no teclado tende a promover um movimento em graus conjuntos). Esses elementos relacionados ao "modo mecânico" foram incorporados ao nosso conceito de "domínio", indo da resposta inicialmente sensorial em direção ao controle manipulativo. Entre outros termos cunhados por Bunting, estão o "especulativo" e o "simbólico". O que ele chama de "a linguagem comum da música" é o nosso "vernacular". Assim, começamos a ter algumas categorias nas quais podíamos agrupar as composições. No entanto, não era nosso desejo que fossem apenas rótulos, mas partes de um esquema dinâmico de desenvolvimento. Posso estar errado, mas me lembro de ter enviado um cartão postal para June, quando eu estava de férias em algum lugar, dizendo "é uma espiral".

Enfatizamos que a sequência de desenvolvimento é "reativada cada vez que encontramos um novo contexto musical" (SWANWICK; TILLMAN, 1986, p.336). Não é um evento definitivo - por isso, as extremidades abertas da espiral. Isso é muito importante e eu tinha a esperança de que eliminasse a possibilidade de as pessoas pensarem na espiral como estágios rígidos. Parece que foi otimista demais da minha parte. De maneira geral, afirma-se com frequência, de manei- 
ra bastante equivocada, que Piaget pensava que cada "estágio" fosse de alguma forma separado dos demais. Por exemplo, Gardner afirmou que, para Piaget, "a criança nem mesmo tem acesso às suas formas anteriores de compreensão. Uma vez que ela avança para outro estágio, é como se o estágio anterior nunca tivesse acontecido" (GARDNER, 1993, p.26-27). Hargreaves, Marshall e North (2003, p.153) também se referem às "descontinuidades do desenvolvimento no pensamento no estilo piagetiano". Esta curiosa interpretação errônea e generalizada de Piaget é contestada por ele explicitamente. Por exemplo, ao escrever sobre o desenvolvimento infantil e o que ele chama de estruturas sucessivas (sensório-motoras, simbólicas, pré-conceituais, intuitivas e racionais), Piaget (1951, p.291) nos diz:

É essencial entender como cada um desses comportamentos continua no subsequente, de um equilíbrio inferior em direção a um superior. É por essa razão que, em nossa opinião, uma análise estática de níveis descontínuos e estratificados é inaceitável.

Em publicações posteriores, usei o termo "camadas" para evitar "níveis" e, certamente, para evitar a ideia de "estágios" estáticos.

Frequentemente, acredita-se que Vygotsky contesta a visão piagetiana do desenvolvimento como um desdobramento de um organismo sem referência ao ambiente cultural e físico (HARGREAVES; ZIMMERMAN, 1992). Mas também existem fortes semelhanças entre Piaget e Vygotsky. Este último concebia o desenvolvimento como uma espiral e pensava que as crianças passavam pelo mesmo ponto a cada nova revolução enquanto avançavam para um nível superior (VYGOTSKY, 1978, p.56). Assim como Piaget, Vygotsky via o desenvolvimento como um processo dialético complexo que incorpora transformações qualitativas.

\section{Uma anomalia}

Os três elementos - materiais, expressão e forma - revelaram-se mais complexos durante este estudo. Inicialmente, a simples associação da expressão com a acomodação e da forma com a assimilação parecia se sustentar. Criar uma frase musical expressiva é "simular" que os sons têm caráter expressivo, que imitam algo (tendência de acomodação). A atividade do jogo imaginativo envolvida na construção de relações entre essas frases implica assimilá-las em nossos próprios esquemas de como as coisas são. Mas o conceito de espiral envolve dois lados, bem como um conjunto de relações verticais. Tentei resolver essa questão em meu livro de 1994, Musical Knowledge: intuition, analysis and music education (ver p.87). Cada camada representa uma mudança qualitativa em relação à anterior: do envolvimento sensorial à imitação reprodutiva, ao jogo estrutural. Mas dentro de cada camada, embora haja uma forte tendência em direção a uma ou outra, também existe uma dialética entre assimilação e acomodação. $O$ discurso musical em qualquer camada depende da interação dinâmica entre ambos os lados da espiral.

Do prazer inicial assimilativo de executar, explorar e reagir aos sons, desenvolve-se a dimensão acomodativa correspondente, uma capacidade de controlar e manipular os sons. Com os sons sob controle, a expressão musical se torna 
possível: a princípio espontânea e talvez aleatória, mas depois mais convencional, adaptando-se aos lugares-comuns vernaculares. Esses procedimentos convencionais são assimilados em um mundo imaginativamente lúdico de surpresas e expectativas, que podem ser integradas às configurações culturalmente estabelecidas dentro de estilos ou idiomas específicos.

\section{Cumulativo e qualitativo}

Nosso modelo é obviamente cumulativo: cada camada depende da presença de camadas anteriores. Por exemplo, não poderíamos compor ou improvisar uma peça expressiva sem controle manipulativo, embora seja possível, naturalmente, ter controle manipulativo sem nenhum traço de expressividade, onde o foco está nas notas, não nas frases. Portanto, não é nenhuma surpresa encontrar várias camadas interativas presentes no mesmo evento musical. $E$ as camadas que encontramos no desenvolvimento da compreensão musical das crianças, conforme revelado em suas composições, são as próprias camadas do discurso musical.

É importante perceber que a sequência de desenvolvimento é essencialmente qualitativa. $O$ fato de este estudo ter analisado 745 composições de crianças não significa, de forma alguma, que ele seja quantitativo. O que estávamos observando era o surgimento de qualidades, características ou tipicidades. Essa é uma abordagem muito diferente da avaliação da produção musical por meio da atribuição de notas numéricas, procedimento que parece endêmico em muitas audições e provas. Os números e gráficos do artigo original são simplesmente as frequências das qualidades observadas entre as crianças que trabalharam com June. Estes não seriam, necessariamente, os mesmos em outros contextos.

\section{Olhando para frente}

Abaixo está uma versão das camadas convertidas em uma ferramenta de avaliação. Essas listas de critérios se mostraram úteis na avaliação do trabalho dos alunos em relação à composição, à apreciação e à performance. Podemos ver quantas camadas estão envolvidas e quais delas são particularmente evidentes nas produções dos alunos. Para alguns colegas, pode ser um passo grande demais, especialmente a tentativa de avaliar a camada do "valor". Nesse caso, talvez a Figura 1 (abaixo) seja mais útil.

\section{Camadas cumulativas para a avaliação da produção e apreciação musicais}

Camada 1 As pessoas apreciam/exploram sons;

Camada 2 elas classificam/controlam sons;

Camada 3 elas identificam/produzem formas expressivas, clima/atmosfera;

Camada 4 elas identificam/produzem formas expressivas dentro de convenções musicais compartilhadas;

Camada 5 elas percebem/produzem formas expressivas em relações de transformação, contraste ou surpresa;

Camada 6 elas localizam relações estruturais dentro de idiomas ou estilos específicos; 
Camada 7 sua percepção/produção musical mostra forte identificação pessoal e comprometimento;

Camada 8 elas se relacionam com a música de maneira contínua, original e com independência engajada.

Outros professores e pesquisadores usaram o modelo como ferramenta de avaliação.

Há espaço, aqui, para citar apenas um desses estudos. Cecília Cavalieri França elaborou critérios de avaliação semelhantes para comparar os níveis de compreensão musical em diferentes atividades. Seu estudo da produção musical de vinte crianças em uma escola de música de Belo Horizonte (MG), Brasil, sugere que a performance geralmente evoca níveis mais baixos de compreensão musical, bastante diferentes daqueles alcançados por meio da composição ou da apreciação (SWANWICK; FRANÇA, 1999). Talvez o foco na performance seja problemático dentro do programa de ensino musical, a menos que os alunos consigam trabalhar em um nível técnico no qual estejam livres para exercer o julgamento interpretativo e tomar decisões musicais.

É claro que só é possível comparar atividades se tivermos uma visão genérica do que se entende por compreensão musical. Este não é o caso de muitos dos testes de habilidade musical mais antigos, que registram o número de respostas "certas" a fragmentos musicais (ou meramente sonoros). Frequentemente, esses testes também são prejudicados por certas conclusões, como a de que a percepção do ritmo se desenvolve antes da percepção de altura. Essas observações tentam cotejar pontuações de testes bastante diferentes, como se comparássemos as leituras de pressão dos pneus de um carro com o nível do óleo. Nesses casos, não existe uma teoria que articule o conceito de compreensão musical ou "musicalidade" - justamente o resultado que estávamos tentando alcançar. Espero que você sinta que contribuímos de alguma forma, June!

Olhando para o passado (e para o futuro), podemos dizer, com alguma segurança, que:

- é possível interpretar o desenvolvimento musical como sendo composto de camadas cumulativas, cada uma trazendo uma qualidade adicional que interage com as demais camadas;

- após terem passado da primeira infância, os alunos podem transitar livremente entre quaisquer camadas qualitativas, desde que as atividades não sejam restritivas. Quanto mais rica a atividade, maior a probabilidade de ocorrer desenvolvimento musical;

- a sequência de desenvolvimento é recorrente e será reativada a cada experiência e em novos contextos musicais;

- a compreensão acerca do desenvolvimento musical é útil para a construção curricular e para a organização de atividades educacionais;

- a consciência da natureza das camadas de compreensão musical pode melhorar nossa interpretação da produção musical e das percepções musicais dos alunos; 
- a integração entre composição, performance e apreciação da música produzida por outras pessoas pode ser positiva para o desenvolvimento;

- Além de fornecer modelos e estruturas musicais em contextos culturais específicos (lado direito da espiral), aos quais o aluno pode se acomodar, é importante deixar espaço para a atividade assimilativa, onde o aluno possa exercer a tomada de iniciativa (lado esquerdo). Entre outros, John Paynter (1970) foi o pioneiro em atividades que ampliaram o lado esquerdo, ao passo que muito do ensino de música tradicional tende a ser realizado à direita.

A seguinte citação resume meu ponto de vista a respeito dessas questões. Peço desculpas por usar palavras de minha própria autoria, mas acredito que elas conseguem comunicar com a maior clareza possível algo que considero importante.

O desenvolvimento futuro da educação musical talvez não dependa tanto das escolas da forma como as conhecemos, mas das oportunidades nas comunidades locais e nas comunidades globais da "rede". O desenvolvimento musical provavelmente ocorrerá em contextos cada vez mais pluralizados e podemos esperar que as suposições e teorias existentes sejam ainda mais desafiadas por essa pluralidade. Na verdade, pode-se argumentar que o conceito de desenvolvimento não tenha utilidade para a educação musical em algumas culturas. Porém, parece mais provável que, mesmo em um mundo onde a aprendizagem da música e os encontros musicais assumem várias formas, ainda pode haver a necessidade de amplas teorias gerais sobre a música e sobre o desenvolvimento musical, sustentadas por conceitos interculturalmente compartilhados sobre o valor e a função da música, continuamente testadas a partir de evidências. Sem essas teorias, por mais contestadas que sejam, pesquisas isoladas podem carecer de coerência e esbarrar em obstáculos para encontrar relevância profissional no campo da educação musical. (SWANWICK, 2016, p.124).

\section{Uma possibilidade para a avaliação de currículos e alunos}

A sequência de desenvolvimento que propusemos em 1986 representa uma dimensão a ser considerada pelos educadores musicais: a natureza da compreensão musical dos alunos. O trabalho anterior do autor chamou a atenção para uma segunda dimensão, as atividades por meio das quais a compreensão é desenvolvida e mantida, expressas no modelo C(L)A(S)P (SWANWICK, 1979).

Podemos imaginar as dimensões combinadas, conforme apresentadas na matriz da Figura 1 (publicada pela primeira vez em SWANWICK, 1994, p.161). 


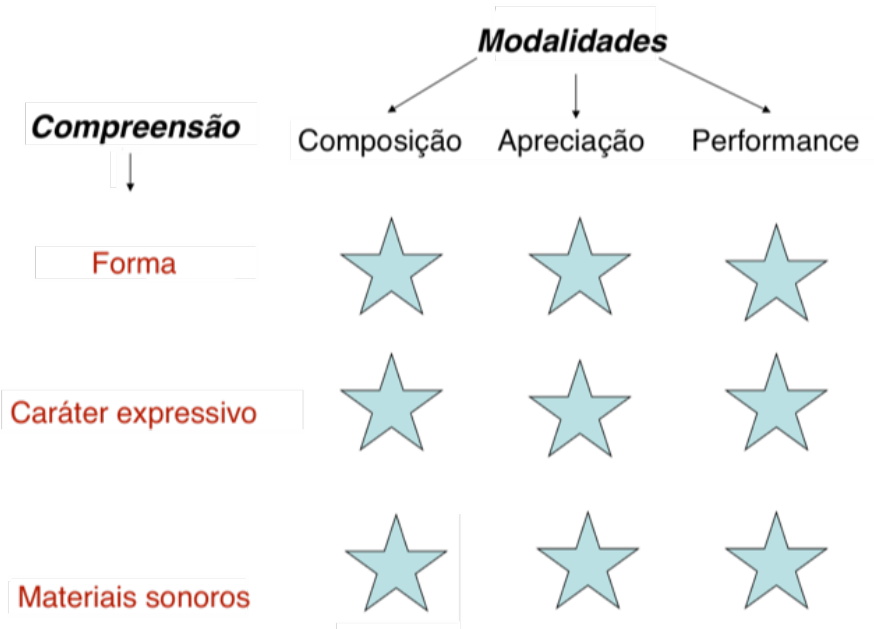

Figura 1

A camada do "valor" não está representada aqui. Podemos definir objetivos, observar os resultados nesta "constelação" e gostar de transitar nela. Mas, assim como ocorre com a felicidade, o "valor" surge quando estamos fazendo algo mais. É o objetivo final da educação musical e não podemos ensiná-lo, apenas esperar que seja captado pelas outras camadas e pela nossa própria atitude.

As nove estrelas da matriz oferecem ao menos uma maneira descomplicada de avaliar qualquer atividade de educação musical: um ensaio de um coral ou banda instrumental, uma aula de instrumento ou de canto, composição ou improvisação, ou a apreciação de uma música. Quantas estrelas brilham e com que frequência? Com o tempo, essas observações devem dar uma ideia do que mencionei no início como aquele "valor agregado" nas trocas entre professores e alunos.

Concluo com uma nota pessoal: durante esses 35 anos, estive envolvido com a música como coralista, trombonista, organista, pianista, maestro e professor. Em todos esses contextos, o conhecimento dessas camadas de compreensão musical forneceu insights e orientou meu envolvimento, bem como meu desenvolvimento. Durante os últimos meses de lockdown da Covid-19, meu filho me enviou uma cópia das Variações Goldberg, de Bach. Portanto, aqui estou eu entre as estrelas da performance no lado manipulativo da camada de materiais sonoros.

Algumas dessas variações vão além das minhas possibilidades, especialmente aquelas escritas para dois teclados, onde duas mãos que compartilham um teclado muitas vezes colidem uma com a outra. No entanto, após prática cuidadosa, algumas dessas variações podem ser administradas, e percebi que não são simplesmente cânones em vários intervalos e outras variações na linha de baixo do tema, a Aria. São artefatos líricos e expressivos que, executados em um andamento apropriado (pode haver várias possibilidades) com fraseado cuidadoso e consistente e uma consciência do cânone e de outras formas, geram grande prazer e promovem um forte senso de valor. Por exemplo, as variações 4 e 22 são 
permeadas por gestos (frases) de intervalos decrescentes (principalmente quartas e quintas) que, tocados no tempo Alla Breve, comunicam um caráter expressivo pacífico e um forte senso de coerência estrutural. Magnífico!

Talvez eu gravite para longe dessas estrelas performáticas, mergulhe nas gravações de Glenn Gould e voe pelo espaço rumo à modalidade da apreciação. Duvido que tente compor cânones, mas quem sabe? Ao menos eu sei o que existe lá fora no universo musical. 


\section{REFERÊNCIAS}

BUNTING, R. The common language of music. Music in the secondary school curriculum. York: York University, 1977.

GARDNER, H. The unschooled mind. London: Fontana, 1993.

HARGREAVES, D. J.; MARSHALL, N. A.; NORTH, A. C. Music education in the twenty-first century: a psychological perspective. British Journal of Music Education, v. 20, n. 2, p. 147-163, 2003.

HARGREAVES, D. J.; ZIMMERMAN, M. P. Developmental theories of music learning. In: Handbook of Research on Music Teaching and Learning. New York: Schirmer Books, 1992. p. 377-389.

PAYNTER, J.; ASTON, P. Sound and silence: classroom projects in creative music. Cambridge: Cambridge University Press, 1970.

PIAGET, J. Play, dreams and imitation in childhood. New York: Norton and Co., 1951.

SWANWICK, K. A basis for music education. London: Routledge, 1979.

SWANWICK, K. Musical knowledge: intuition, analysis and music education. London and New York: Routledge, 1994.

SWANWICK, K. In MENC Handbook of Research on Music Learning. New York: Oxford University Press, 2011. v. 1, p. 140-172.

SWANWICK, K. A Developing Discourse in Music Education: the selected work of Keith Swanwick. Abingdon and Oxford: Routledge, 2016.

SWANWICK, K.; FRANÇA, C. Composing, performing and audience-listening as indicators of musical understanding. British Journal of Music Education, v. 16, n. 1, p. 5-19,1999.

SWANWICK, K.; TILLMAN, J. The Sequence of Musical Development: A Study of Children's Composition. British Journal of Music Education, v. 3, n. 3, p. 305-339,1986.

VYGOTSKY, L. S. Mind in society: the development of higher psychological processes. Cambridge: Harvard University Press, 1978. 